filter medium up to an arbitrary position in cake

$\omega_{0}$

$=$ net solid volume of entire cake

per unit area $\left[\mathrm{cm}^{3} / \mathrm{cm}^{2}\right]$

$\left[\mathrm{cm}^{3} / \mathrm{cm}^{2}\right]$

Literature Cited

1) Carman, P. C.: Trans. Instn. Chem. Engrs. (London), 15, 150 (1937).

2) Grace, H. P.: Chem. Eng. Progr., 49, 303, 367 (1953).

3) Kozicki, W., C. J. Hsu and C. Tiu: Chem. Eng. Sci., 22, 487 (1967).

4) Kozicki, W., C. Tiu and A. R. K. Rao: Can. J. Chem. Eng., 46, 313 (1968).

5) Kozicki, W., A. R. K. Rao and C. Tiu: Chem. Eng. Sci., 27, 615 (1972).

6) Okamura, S. and M. Shirato: Kagaku Kögaku, 19, 104

(1955).

7) Shirato, M., T. Aragaki, R. Mori and K. Sawamoto: J. Chem. Eng. Japan, 1, 86 (1968).

8) Shirato, M., T. Aragaki, R. Mori and K. Imai: Kagaku Kögaku, 33, 576 (1969).

9) Shirato, M., T. Aragaki, K. Ichimura and N. Ootsuji: J. Chem. Eng. Japan, 4, 172 (1971).

10) Shirato, M., T. Aragaki, E. Iritani, S. Fujiyoshi and S. Nanda: ibid., 10, 54 (1977).

11) Shirato, M., T. Aragaki and E. Iritani: ibid., 13, 61 (1980).

12) Tiller, F. M.: Chem. Eng. Progr., 51, 282 (1955).

13) idem: AIChE J., 4, 170 (1958).

14) Tiller, F. M. and M. Shirato: ibid., 10, 61 (1964).

(Presented at the 45th Annual Meeting of The Soc. of Chem. Engrs., Japan at Osaka, April 2, 1980).

\title{
OPTIMAL PLANNING OF WATER ALLOCATION IN INDUSTRY
}

\author{
NORIHIRO TAKAMA, TAKAFUMI KURIYAMA, \\ KATSUO SHIROKO AND TOMIO UMEDA \\ Chiyoda Chemical Engineering \& Construction Co., Ltd., \\ Yokohama 230
}

\begin{abstract}
This paper presents a practical planning method for optimal water allocation in a total system consisting of water-using and water-treating process units. The method uses a heuristic rule and a linear programming algorithm. The heuristic rule regarding a sequence of process units is used to simplify an integrated system structure. The algorithm uses repeatedly a linear programming technique to solve a linearized problem for a set of constant values of some parameters. By using the combination of these two approaches, a total system structure is determined so as to minimize the total cost associated with fresh water and water treatment subject to constraints derived from material balances and interrelationships among process units. The method is illustrated by its application to an optimal water allocation problem in a petroleum refinery.
\end{abstract}

\section{Introduction}

Before the environmental issue became a matter of social awareness, a large amount of water was used in chemical, petrochemical, petroleum refining, and other process industries. Recently, however, environmental protection and conservation of water resources have increased their importance, providing process industries with a strong incentive for efficient water use. Many studies have been made for achieving the goal of extensive water reuse and finally zero discharge in various process industries ${ }^{1,3,5,7)}$. As to optimizations for wastewater-treating systems, several

Received April 11, 1980. Correspondence concerning this article should be addressed to N. Takama. attempts ${ }^{4}$ have also been made by using systems approaches. However, the studies presented so far only cover wastewater-treating systems in which the quality and quantity of wastewater were given beforehand.

For efficient use of water in process industries, a general optimization problem for water reuse should be considered in a total system consisting of waterusing and water-treating subsystems. In the authors' previous paper $^{6)}$, a general problem of optimal water allocation was formulated as a mathematical programming problem and was solved by using a direct search method. The approach was a general one applicable to various engineering problems of a relatively small size. 
From engineering viewpoints, however, a specific but efficient method has been required for solving large-scale planning problems of optimal water allocation. This paper presents a method for optimizing large-scale water allocation in process idustries. Since a generally formulated problem involves a materialbalancing problem in a highly complex structure, two approaches to problem-solving are considered: one is directed toward simplifying the complex structure by applying heuristic rules to the sequence of water-using and water-treating units, and the other toward solving the planning problem by applying the linear programming technique (LP, henceforth). To illustrate the present method, a planning problem of optimal water allocation for a petroleum refinery is considered as a practical example. The result is compared with that for a conventional case.

\section{Statement of Problem}

On the basis of water flow, a process system is, in general, considered to be comprised of two major subsystems as shown in Fig. 1: water-using subsystem to which water is supplied and/or from which wastewater is discharged, and a water-treating subsystem which treats raw water and/or wastewater. A policy for efficient water use and treatment should be determined so as to minimize the sum of costs of buying raw water and of treating raw and wastewater.

Figure 2 shows the general structure of the system for water use and treatment. The 1 st and $N$-th subsystems are respectively a source of raw water supplied to any subsystem and a final holding basin which collects effluent water from all other subsystems and discharges it to the environment. Each subsystem has one mixing and one splitting point, and a flow from any splitting point is directed to any other mixing point. In this respect, the subsystems are ordered from water-using subsystems to water-treating subsystems without losing the generality of the system structure.

The optimization problem of a process system for water use and treatment is defined as a problem in which a system structure and process conditions of subsystems composing the system are both determined so as to optimize a given objective function. Since the problem is large-scale and complex, it is expedient to decompose the problem into the following planning and design problems by applying a so-called twolevel approach.

Planning problem: to determine an optimal system structure by allocating water under the condition that design variables in subsystems are given as the result of optimization on the lower level.

Design problem: to determine an optimal process condition by specifying design variables for each sub-

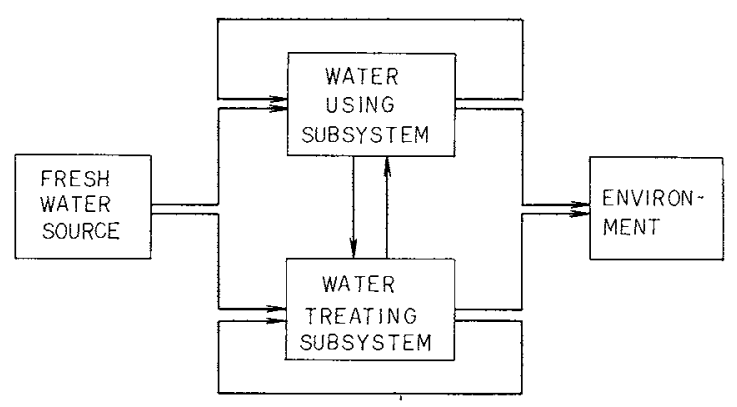

Fig. 1 System for water use and treatment in industry

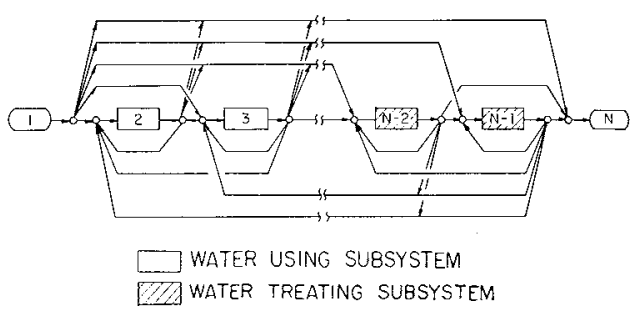

Fig. 2 General system structure for water use and treatment in industry

system under the condition that water allocation is given as the result of optimization on the upper level.

The present study is concerned with the planning problem of optimal water allocation. It is assumed that a process condition in each subsystem determined on the lower level is given beforehand in the following discussion. That is, for each water-using subsystem, the amount of feed water and the quality and quantity of effluent water are fixed. For each water-treating subsystem, the quality of treated water is fixed. Furthermore, the permissible level for the quality of feed water is fixed for each subsystem. Like other planning problems, the present problem is also a largedimensional optimization problem subject to a set of many constraints. Such a problem has been solved in practice by using LP, if the problem under consideration is defined as an optimization problem suitable for the effective application of LP.

The planning problem, in general, is defined as follows:

$\begin{array}{lll}\underset{\{\boldsymbol{x}, \boldsymbol{q}\}}{\text { Minimize }} & f(\boldsymbol{q}) & \\ \text { subject to } & \boldsymbol{g}(\boldsymbol{q}) & =\mathbf{0} \\ & \boldsymbol{p}(\boldsymbol{x}, \boldsymbol{q}) & =\mathbf{0}\end{array}$

and

$$
\boldsymbol{h}(\boldsymbol{x}, \boldsymbol{q}) \quad \leqq \mathbf{0}
$$

where $x$ and $\boldsymbol{q}$ are the vectors associated with pollutant concentrations and flow rates, respectively. Equations (2) and (3) describe water and pollutant balance relationships at mixing and splitting points. The inequality constraint described by Eq. (4) is imposed to define an feasible region. 


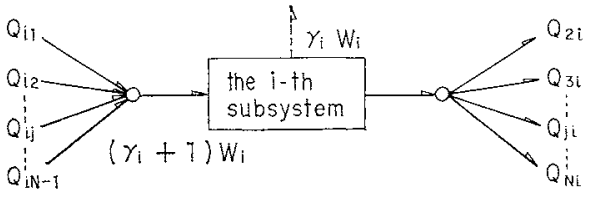

Fig. 3 Feed and effluent streams for the $i$-th subsystem

As shown below, the problem defined above can be reformulated in such a way that LP is iteratively applicable.

$\underset{\{\boldsymbol{x}\}}{\operatorname{Minimize}}\left(\begin{array}{cl}\underset{\{\boldsymbol{q} \mid \boldsymbol{x}\}}{\text { Minimize }} & \boldsymbol{F}^{T} \cdot \boldsymbol{q} \\ \text { subject to } & =\mathbf{0} \\ \mathbf{G} \cdot \boldsymbol{q} & =\mathbf{0} \\ \boldsymbol{P}(\boldsymbol{x}) \cdot \boldsymbol{q} & \leq \mathbf{0}\end{array}\right.$

where the objective function and the water balance relationship are linearized as shown in Eqs. (5) and (6), corresponding to Eqs. (1) and (2), respectively. By giving a certain value to $\boldsymbol{x}$ in Eqs. (3) and (4), the pollutant balance relationship and inequality constraint are linearized as shown in Eqs. (7) and (8). For a given value of $\boldsymbol{x}$, an inner optimal solution (LP solution, henceforth) for a linearized problem shown in the brackets is obtained by using LP. An optimal solution for the overall planning problem is obtained by determining $\boldsymbol{x}$ so that the LP solution is minimized.

\section{Method for Solution}

The method presented here comprises two approaches to tackling large and complex problems: one is to simplify the complex structure by using heuristic rules, and the other is to solve the planning problem by the iterative application of LP. Details of the method are described below.

\section{1 Linearization of problem}

The optimization problem under consideration is defined by the following Eqs. (9) to (13) expressing an objective function and the behavior of water-using and water-treating subsystems. The objective function expresses total annual cost as follows:

$$
C=\lambda \cdot \sum_{i=M+1}^{N-1}\left(C_{v i} \cdot W_{i}\right)+\sum_{i=M+1}^{N-1}\left(C_{o i} \cdot W_{i}\right)+C_{w} \cdot W_{1}
$$

The first and second terms on the right-hand side are annual fixed cost and operating cost for the watertreating subsystems, respectively. A constant $\lambda$ involved in the first term denotes a factor associated with the annual fixed cost. The last term is the cost of raw water.

As shown in Fig. 3, the water balance relationships at mixing and splitting points associated with the $i$-th subsystem are represented by

$$
\begin{aligned}
& W_{i}\left(\gamma_{i}+1\right)=\sum_{j=1}^{N-1} Q_{i j} \quad(i=2, N) \\
& W_{i} \quad=-\sum_{j=2}^{N} Q_{j i} \quad(i=1, N-1)
\end{aligned}
$$

where $W_{i}$ and $Q_{i j}$ are the flow rate of effluent water from the $i$-th subsystem and that of split water from the $j$-th to the $i$-th subsystem, respectively. $\quad \gamma_{i}$ is a preset fraction of unrecoverable water due to evaporation, entrainment and so on. Since the amount of water used in each water-using subsystem is determined in the design problem as described in the previous section, the flow rate of effluent water from each water-using subsystem $W_{i}(i=2, M)$ is a given constant in Eqs. (10) and (11).

Feed water to each subsystem should satisfy a constraint on the quality of water acceptable to the waterusing and water-treating subsystems. In particular, feed water to the imaginary output subsystem should satisfy current national or local discharge regulations. From this point of view, the following inequality constraint associated with the $k$-th pollutant is imposed on feed water to the $i$-th subsystem:

$$
\begin{aligned}
\sum_{j=1}^{N-1}\left(x_{j}^{k} \cdot Q_{i j}\right)-z_{i}^{k} \cdot\left(\gamma_{i}+1\right) W_{i} \leqq 0 \\
(i=2, N)(1 \leqq k \leqq K)
\end{aligned}
$$

where $x_{i}^{k}$ and $z_{i}^{k}$ are the $k$-th pollutant concentration in effluent water from the $j$-th subsystem and a limit for the $k$-th pollutant concentration in feed water to the $i$-th subsystem, respectively. Since the limits are determined in the design problem, $z_{i}^{k}$ 's in Eqs. (12) are given constants. $x_{j}^{k}$ s for the pollutants treated in the $j$-th subsystem are also constants determined in the design problem. However, $x_{j}^{k e}$ s for the pollutants untreated in the $j$-th subsystem are determined by the following equation associated with the pollutant balance relationship:

$$
\begin{array}{rr}
W_{j}\left(\gamma_{j}+1\right) x_{j}^{k} & =\sum_{l=1}^{N-1}\left(x_{l}^{k} \cdot Q_{j l}\right) \\
(M+1 \leqq j \leqq N-1, & 1 \leqq k \leqq K)
\end{array}
$$

By fixing $x_{j}^{k}$ 's for the untreated pollutants, Eqs. (12) and (13) are linearized. Under the linear constraints described by Eqs. (10) to (13), optimal values of the independent variables $Q_{i j}$ 's are obtained by applying LP so as to minimize the linear objective function described by Eq. (9).

\section{2 Iterative application of $L P$}

The iterative application of LP is one of the most effective approaches to solving non-linear, largedimensional, and constrained optimization problems such as the present problem ${ }^{21}$. The planning problem of optimal water allocation is linearized by fixing the concentrations $x_{j}^{k}$, s for the untreated pollutants which are determined by Eq. (13). The $x_{j}^{k}$ 's for the untreated pollutants are expressed by $\boldsymbol{x}$ 
in the preceding section. An LP solution $\phi^{(x)}$ for the linearized problem is obtained for a given value of $\boldsymbol{x}^{(n)}$. An optimal value $\boldsymbol{x}^{*}$ is determined in such a way as to obtain a minimal LP solution $\phi^{*}$, which is an optimal solution for the overall planning problem.

The direction of modifying the value for $\boldsymbol{x}^{(n)}$ depends on the value of the left-hand side (LHS) ${ }_{k, i}$ of Eq. (12). According to the value of (LHS) $)_{k, i}$, which is obtained by solving a linearized problem under a given value of $\boldsymbol{x}^{(n-1)}$, the direction of modifying $\boldsymbol{x}^{(n)}$ can be determined as follows:

i) $(\text { LHS })_{l, i}=0$

The $k$-th pollutant concentration in the feed water to the $i$-th subsystem is equal to its limitation. Since the objective function can be improved by relaxing the limitation, the value of $x_{i}^{k}$ should be increased.

ii) $(\text { LHS })_{k, i}<0$

The $k$-th pollutant concentration in the feed water to the $i$-th subsystem is smaller than the concentration in the effluent water from the $i$-th subsystem. The value for $x_{i}^{k}$ should be decreased to the $k$-th pollutant concentration in the feed water.

An increment or decrement for modifying $\boldsymbol{x}^{(n)}$ is given by the following equation:

$$
\Delta x=\alpha\left(x_{\max }-x_{\mathrm{min}}\right)
$$

where $\boldsymbol{x}_{\max }$ and $\boldsymbol{x}_{\min }$ are maximum and minimum concentration fed to the corresponding subsystem, respectively, and $\alpha$ is a fraction given beforehand. The computational procedure is shown in Fig. 4.

\section{3 Heuristic rule for stream reduction}

Since the planning problem of optimal water allocation has a large number of independent variables which leads to a highly complex network structure, it is better for practical problem-solving to reduce the number of independent variables and simplify the network structure as much as possible. This can be realized by ruling out some streams by means of appropriate heuristic rules such as the following.

- To rule out raw water streams directed to wastewater-treating subsystems and a final holding basin.

- To rule out a recycling stream around each subsystem.

- To rule out streams from one water-using subsystem with milder pollutant limits to the other water-using subsystems with severer limits.

- To rule out streams from one water-treating subsystem with severer pollutant limits to the other subsystems with milder limits.

These heuristic rules have been developed from practical and economical viewpoints. It is expected that others will be developed by more extensive studies.

\section{Illustrative Example}

Application of the method is made here to a planning

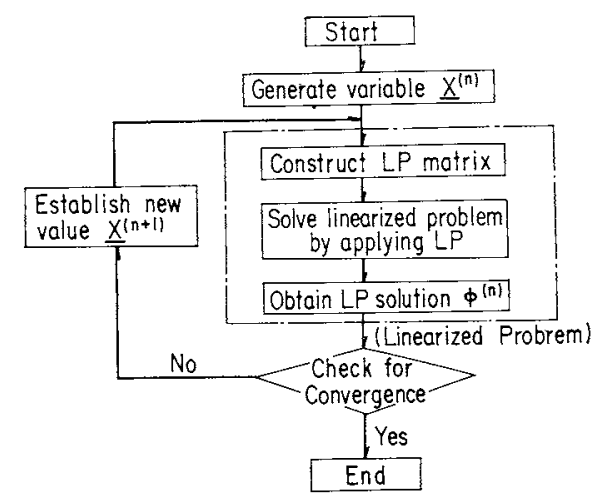

Fig. 4 Computational procedure for optimization

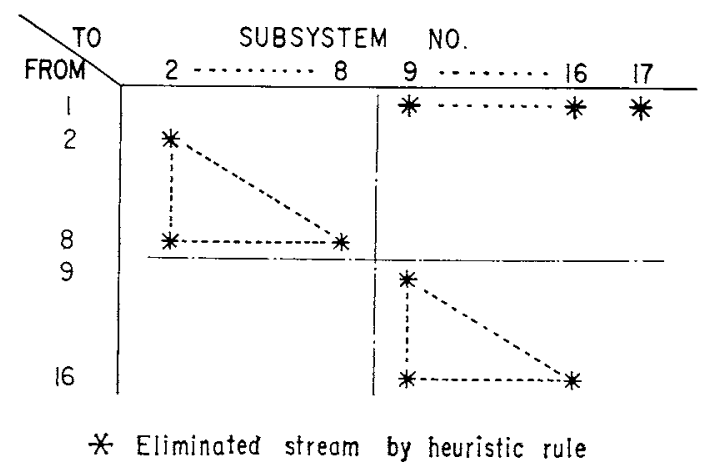

Fig. 5 Simplification of stream matrix

problem of optimal water allocation in a 200,000 BPSD petroleum refinery.

The system under consideration consists of waterusing and wastewater-treating processes, where water quality is expressed by the concentrations of five pollutants, $\mathrm{H}_{2} \mathrm{~S}$, Oil, SS, COD, and TDS. According to the water quality expressed by these pollutants, feed water and effluent water of water-using processes are classified into four and five quality levels, respectively. With respect to the combination of the water quality levels, the water-using processes are decomposed and aggregated into seven water-using subsystems. Eight wastewater-treating subsystems are considered as follows: Foul water strippers with high/ low steam rates, oil separator, activated sludge, coagulation and sedimentation, filter, activated carbon adsorption, and electrodialysis.

Problem-solving is started by reducing the number of streams on the basis of the heuristic rules. Figure 5 shows a stream matrix simplified by applying the rules. The problem is linearized by fixing 16 sets of parameters, $x_{i}^{k}$ and $z_{i}^{k}$. Under specified conditions shown in Table 1, optimal water allocation is determined so as to minimize the annual cost of the system by modifying the values of the above parameters and by iteratively using LP. Starting from the initial values of the parameters determined for a conventional flow scheme, the modification of the parameters is 


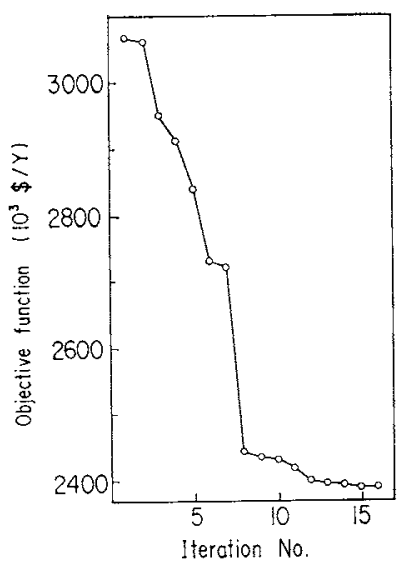

Fig. 6 Convergence of LP solution

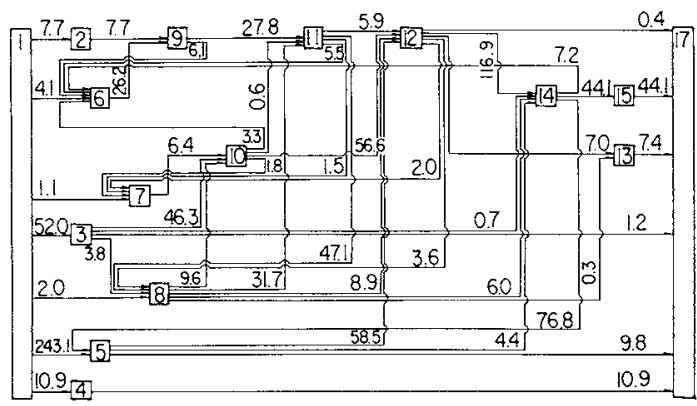

(a) Optimal case

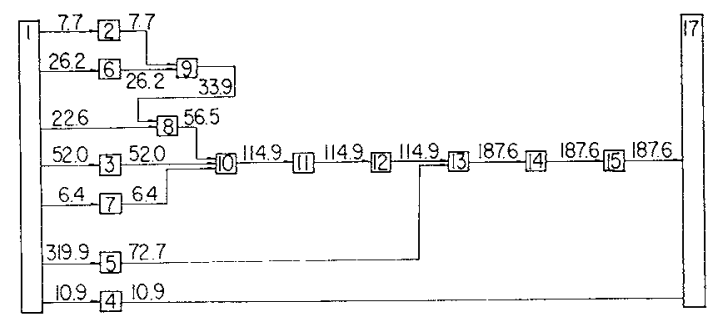

(b) Conventional case

Fig. 7 Comparison of system structures for optimal and conventional cases

carried out by solving linearized problems iteratively.

Figure 6 shows the convergence of LP solutions toward a final solution with respect to the number of iterations.

The final solution is obtained through 16 iterations. An optimal value of the objective function and an optimal flow scheme are shown in Table 2 and Fig. 7, respectively. For comparison purposes, a conventional case is also shown. The application of the method results in great improvements as shown below:

- The annual cost is decreased by $42 \%$ of that for the conventional case.

- The amount of raw water is decreased by $28 \%$ of that for the conventional case.

- Water multi-use without treatment is practical, thus reducing treatment cost.

- Water recovery with a small degree of treatment is practical to reduce the amount of raw water.

- Excessive and costly treatment is avoided, thus
Table 1 Specified conditions for optimization

A) Subsystem data for feed water

\begin{tabular}{|c|c|c|c|c|c|c|}
\hline $\begin{array}{l}\text { Sub- } \\
\text { system }\end{array}$ & $\begin{array}{l}\text { Feed } \\
\text { flow rate } \\
\text { [ton/hr] }\end{array}$ & $\begin{array}{c}\mathrm{H}_{2} \mathrm{~S} \\
{[\mathrm{ppm}]}\end{array}$ & $\begin{array}{c}\text { ollutant } \\
\text { OIL } \\
\text { [ppm] }\end{array}$ & $\begin{array}{c}\text { oncentr } \\
\text { SS } \\
\text { [ppm] }\end{array}$ & $\begin{array}{l}\text { ion limi } \\
\text { COD } \\
\text { [ppm] }\end{array}$ & $\begin{array}{l}\text { TDS } \\
\text { [ppm] }\end{array}$ \\
\hline 1 & - & - & - & - & - & - \\
\hline $2 \mathrm{~B} 1$ & 7.7 & 1 & 1 & 5 & 5 & 200 \\
\hline $3 \mathrm{~B} 2$ & 52.0 & 1 & 1 & 5 & 5 & 200 \\
\hline $4 \mathrm{~B} 3$ & 10.9 & 1 & 1 & 5 & 5 & 200 \\
\hline $5 \mathrm{C}$ & $320.0^{* *}$ & 2 & 1 & 5 & 10 & 500 \\
\hline $6 \mathrm{Pl}$ & 26.2 & 10 & 100 & 15 & 50 & 1000 \\
\hline $7 \mathrm{P} 2$ & 6.4 & 10 & 10 & 25 & 70 & 1000 \\
\hline $8 \mathrm{D}$ & 56.5 & 50 & 30 & 35 & 70 & 1000 \\
\hline 9 FS1 & * & 20000 & - & - & - & - \\
\hline $10 \mathrm{FS} 2$ & * & 500 & - & - & - & - \\
\hline $11 \mathrm{OS}$ & * & - & 200 & - & - & - \\
\hline $12 \mathrm{AS}$ & * & 10 & 20 & - & 100 & - \\
\hline $13 \mathrm{CS}$ & * & - & 15 & 3000 & - & - \\
\hline $14 \mathrm{FL}$ & * & 一 & 10 & 30 & - & - \\
\hline $15 \mathrm{AC}$ & * & - & 3 & 5 & 25 & - \\
\hline $16 \mathrm{ED}$ & * & 1 & 1 & 1 & 10 & 10000 \\
\hline 17 & $*$ & 10 & 1 & 5 & 10 & - \\
\hline
\end{tabular}

B) Subsystem data for effluent water

\begin{tabular}{|c|c|c|c|c|c|c|}
\hline $\begin{array}{c}\text { Sub- } \\
\text { system }\end{array}$ & $\begin{array}{l}\text { Effluent } \\
\text { flow rate } \\
\text { [ton/hr] }\end{array}$ & $\begin{array}{c}\mathrm{H}_{2} \mathrm{~S} \\
{[\mathrm{ppm}]}\end{array}$ & $\begin{array}{l}\text { Pollutar } \\
\text { OIL } \\
\text { [ppm] }\end{array}$ & $\begin{array}{c}\text { concer } \\
\text { SS } \\
\text { [ppm] }\end{array}$ & $\begin{array}{c}\text { ration } \\
\text { COD } \\
{[\mathrm{ppm}]}\end{array}$ & $\begin{array}{c}\text { TDS } \\
{[\mathrm{ppm}]}\end{array}$ \\
\hline 1 & * & 1 & 1 & 5 & 5 & 200 \\
\hline $2 \mathrm{~B} 1$ & 7.7 & 16400 & 100 & 15 & 50 & 1000 \\
\hline $3 \mathrm{~B} 2$ & 52.0 & 390 & 10 & 25 & 70 & 1000 \\
\hline $4 \mathrm{~B} 3$ & 10.9 & 1 & 1 & 5 & 5 & 2000 \\
\hline $5 \mathrm{C}$ & 72.7 & 2 & 4 & 20 & 20 & 2000 \\
\hline $6 \mathrm{P} 1$ & 26.2 & 16400 & 100 & 15 & 50 & 1000 \\
\hline $7 \mathrm{P} 2$ & 6.4 & 390 & 10 & 25 & 70 & 1000 \\
\hline $8 \mathrm{D}$ & 56.5 & 50 & 100 & 35 & 100 & 1000 \\
\hline 9 FS1 & * & 5 & - & - & - & - \\
\hline $10 \mathrm{FS} 2$ & * & 10 & - & - & - & - \\
\hline 11 os & * & - & 10 & - & - & - \\
\hline $12 \mathrm{AS}$ & $*$ & 0.5 & 1 & - & 20 & - \\
\hline $13 \mathrm{CS}$ & * & - & 1 & 10 & - & 一 \\
\hline $14 \mathrm{FL}$ & * & - & 1 & 5 & - & - \\
\hline $15 \mathrm{AC}$ & $*$ & - & 0.1 & 0.1 & 5 & - \\
\hline 16 ED & $*$ & - & - & - & - & 100 \\
\hline 17 & 一 & - & - & - & - & - \\
\hline
\end{tabular}

C) Economic data

Annual rate of return $[\%] \quad 13.15$

Operating hours [hr/year] 8,000

Fresh water cost [\$/ton] 0.12

\begin{tabular}{ccc} 
Subsystem & $\begin{array}{c}\text { Investment cost } \\
{[\$ / \text { ton } / \mathrm{hr}]}\end{array}$ & $\begin{array}{c}\text { Operating cost } \\
{[\$ / \text { ton] }}\end{array}$ \\
\hline $9 \mathrm{FS} 1$ & 42000 & 1.2 \\
$10 \mathrm{FS} 2$ & 42000 & 1.0 \\
$11 \mathrm{OS}$ & 2,400 & 0.12 \\
$12 \mathrm{AS}$ & 4,000 & 0.24 \\
$13 \mathrm{SC}$ & 2,040 & 0.02 \\
$14 \mathrm{FL}$ & 5,600 & 0.008 \\
$15 \mathrm{AC}$ & 14,800 & 0.4 \\
$16 \mathrm{ED}$ & 56,400 & 0.6
\end{tabular}

* Not to be specified

** Inculuding unrecoverable water due to evaporation, entrainment, and so on.

Table 2 Comparison of optimal and conventional cases

\begin{tabular}{clrr} 
& Op. case & Con. case \\
\hline Objective function & {$\left[10^{3} \$\right.$ year $]$} & 2,389 & 4,116 \\
Investment cost & {$\left[10^{3} \$\right]$} & 6,090 & 11,196 \\
Operating cost & {$\left[10^{3} \$\right.$ /year $]$} & 1,280 & 2,644 \\
Fresh water cost & {$\left[10^{3} \$\right.$ year] } & 308 & 428 \\
\hline
\end{tabular}


reducing treatment cost.

\section{Discussion}

For the repetitive use of LP, the initial value of the parameter $\boldsymbol{x}$ is determined for a conventional flow scheme, and systematically modified according to the activeness of the constraints associated with $\boldsymbol{x}$. In the present example, the optimal solution has been obtained by 16 iterations.

From the practical viewpoint, the optimal flow scheme obtained by using the present method should be simplified by ruling out streams with negligibly small flow rates. A flow scheme derived in this way gives a practical solution.

\section{Acknowledgment}

The authors would like to thank Dr. M. Nishio for his useful suggestions on the present study. The authors are also grateful to Chiyoda Chemical Engineering \& Construction Co., Ltd. for the support of study and for permission to publish the present paper.

\section{Nomenclature}

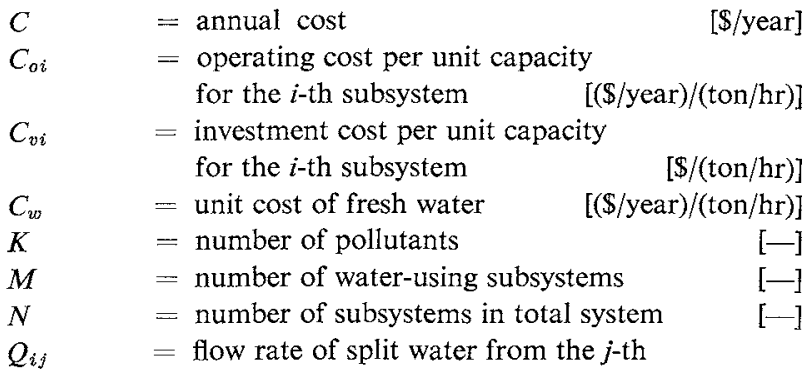

to the $i$-th subsystem [ton $/ \mathrm{hr}$ ] $q$

$W_{i}$

$x_{i}^{k}$

$\boldsymbol{x}$

$z$

$z_{i}^{k}$

$\lambda$

$r_{i}$

$\phi^{(n)}$
$=$ vector associated with flow rate

$=$ flow rate of effluent water from the $i$-th subsystem

$[\mathrm{toh} / \mathrm{hr}]$

[ton $/ \mathrm{hr}]$ effluent water from the $i$-th subsystem

$=$ vector associated with pollutant concentration

$=$ concentration limit for the $k$-th pollutant in feed water to the $i$-th subsystem

$=$ factor for modifying parameters [-]

$=$ factor associated with annual fixed cost [1/year]

$=$ fraction of unrecoverable water in the $i$-th subsystem

$=$ linear programming solution for $\boldsymbol{x}^{(n)}$ at the $n$-th iteration

[\$/year]

\section{Literature Cited}

1) Anderson, D.: Int. Chem. Eng., Symp. Ser., No. 52, 2-11 (1977).

2) Himmelblau, D. M.: "Applied Nonlinear Programming," p. 221, McGraw-Hill Book Company, N. Y., 1972.

3) Kelsey, G. D.: Int. Chem. Eng. Symp. Ser., No. 52, 2-21 (1977).

4) Mishra, P. N., L. T. Fan and L. E. Erickson: Water-1974 (II), AIChE Symposium Series, Vol. 71, No. 145, p. 136 1975.

5) Porter, J. W., J. H. Blake and R. T. Milligan: Proceedings, National Water Reuse Conference, 13F, Washington D. C., 1973.

6) Takama, N., T. Kuriyama, K. Shiroko and T. Umeda: Computers and Chemical Engineering, 4, 251 (1980).

7) Weisberg, E. and D. L. Stockton: Proceedings, National Water Reuse Conference, 13B, Washington D. C., 1973. 